\title{
Determining the Optimum Service Area and Station Location for Personal Mobility Sharing Services
}

\author{
Minhye Choi $^{\circledR a}$, Hunyoung Jung ${ }^{\circledR b}$, and Hyeryeong Lee ${ }^{\odot c}$ \\ ${ }^{a}$ Dept. of Urban Planning \& Engineering, Pusan National University, Busan 46241, Korea \\ ${ }^{b}$ Member, Dept. of Urban Planning \& Engineering, Pusan National University, Busan 46241, Korea \\ ${ }^{c}$ Member, Busan Development Institute, Busan 47210, Korea
}

\section{ARTICLE HISTORY}

Received 16 November 2020

Revised 15 February 2021

Accepted 26 April 2021

Published Online 23 June 2021

\section{KEYWORDS}

Shared mobility service

Stations

Dockless systems

Optimization model

Location allocation model

\begin{abstract}
This study focused on station and dockless systems related to personal mobility sharing services in the midst of which is currently increasing. Based on relevant literatures that operating of these two systems in tandem was more efficient for urban management, a methodological framework was proposed with the combination of determining dockless personal mobility sharing service areas based on user preference and determining the station locations based on potential demand. This framework was applied to Geumjeong-gu, Busan, Korea. The results showed that approximately $33 \%$ of the case areas need to be designated as dockless service areas based on survey data. The required minimum number of stations was calculated by considering the travel distance between users and facilities, and the location of the stations (according to the number of random stations) were determined as a locations condition to minimize the sum of the travel distances. This framework is possible to suggest useful policies for attracting facilities, that is, planning for the number of facilities according to possible inputs from local governments and determining the capacity of stations based on the demand allocated to them.
\end{abstract}

\section{Introduction}

Personal transportation vehicles have become a major component of urban transport in many cities, owing to their active use by travelers. As the use of single-person transportation vehicles running on electric power is spreading, shared business models using e-bicycles and e-scooters are drawing attention. In particular, following the spread of coronavirus disease (COVID-19), the number of e-scooter sharing service users has increased (Kwak, 2020). Many studies have shown that such usages and sharing have positive effects on the economy and environment by reducing urban congestion and harmful emissions (Shaheen and Finson, 2003; Hollingsworth et al., 2019; Luo et al., 2019). In addition, these effects are expected to increase as personal mobility sharing (PMS) services are effectively linking to public transportation services (Nair et al., 2013; Faghih-Imani and Eluru, 2015).

PMS systems are generally introduced as dockless systems (DSs) and the number of DS service providers and the usage of such services have increased significantly (Clewlow, 2019;
Almannaa et al., 2020). DS users can rent and return the device within a service area at little difficulty and this convenience accounts for advantage of DS. However, there is concern that the DS is sensitive to the landscape of service area and can obstruct the movement of other modes of transport (Fang et al., 2018; Gao et al., 2021). This issue persists owing to the difficulty of immediate management and conflicts are intensifying (e.g., in collecting these devices) as local governments regard them as traffic-blocking facilities. The installation of stations as easy-tomanage facilities has been considered as a measurement to resolve these issues. Unlike DS, a station system (SS) being served as PMS has disadvantages requiring users to rent and return the device to/from a designated location and demanding enormous cost associated with the installation and relocation of these stations (Zhang et al., 2019; Kim et al., 2019b). In terms of urban management, it will be expected to have complementary effects with new PMS system that combines DS and SS.

Therefore, to contribute efficient management and safe operation of PMS, this study proposes a framework determining PMS 
service area and location of PMS stations which are optimized by user's preference and potential demand.

\section{Review of Related Research}

Operational characteristics of DS and SS can be examined in detail, as shown in Fig. 1. Various studies have considered ways to determine user-based service areas and station locations. One key factor for successful service adoption in regions where the service has not yet been implemented is the identification of potential demand (Frade and Ribeiro, 2014). Notably, if the DS service range is wide irrespective of the intention to use, and the determination of the number and location of stations does not consider the demand for its service, it can lead to larger drawbacks. In this regard, Sa and Lee (2018) emphasized the need for an effective station location strategy. Their study indicated that underperforming stations had emerged in the case of Seoul City as a result of the indiscriminate deployment of stations in the early stages of introducing shared bicycles. Lin and Yang (2011) and Chen et al. (2015) also argued that station location decisions are key to the success of shared services. Therefore, it can be seen that for PMS to succeed, it is very important to find the station locations and service areas considering the demand.

From research discussing the characteristics of PMS usage and users experience, it is found that PMS is mainly used on university campuses and in commercial and business areas. It is also found useful as a connecting mode to transit systems (Bai and Jiao, 2020). However, the preferences for DS or SS are different by the location of the service used (Lazarus et al., 2019; Li and Tang, 2019). Li and Tang (2019) revealed that users prefer DS at the point of origin and SS at the destination. Lazarus et al. (2019) found that DS users mainly travel from low-density destinations, whereas SS users are mainly active in dense business areas. As a wider range of DS services is possible with fewer devices than SS, it is necessary to operate services efficiently to compensate for disadvantages that may occur in densely populated areas by SS. Accordingly, the station should be located in an area where there observes large groups of commuters and travelers and where users prefer its service, consistent with the arguments of Ji et al. (2020) and Park and Sohn (2017).

Next, we examined earlier studies related to PMS service areas and proper station positioning. In a study on DS service areas, Kim et al. (2019a) proposed setting all areas within the range of influence of road networks connected to major places such as DS service areas, while taking into consideration the slope of the target site and the climbing capability of the personal mobility devices. Tu et al. (2019) pointed out that to promote the use of shared bicycles in a DS service area, the supply should be at a level appropriate to the weather conditions, time of day, and place.

Research for determining the location of a station is generally conducted using location-allocation models based on potential demand. Frade and Ribeiro (2014) estimated bicycle demand by associating characteristics such as travel distance and slope with trip purpose. Subsequent studies, determined the location of a shared station based on potential demand and calculated the size of the station using the maximum coverage location problem (MCLP) (Frade and Ribeiro, 2015). García-Palomares et al. (2012) estimated the potential demand based on population, activity, and public transportation nodule points using a geographic information system. An analysis using the minimum impedance (p-median) and MCLP models based on this network analysis was used to determine the location of a shared bicycle station by scenario. A study by Park and Sohn (2017) compared the p-median and MCLP models, and suggested a method for determining a station location by using taxi information and mobile device data to determine an optimal location for shared bicycle stations that could replace short-distance passenger traffic. Zhang et al. (2019) proposed a framework for the installation of electric fences through the MCLP to address inappropriate parking behaviors when returning DS-shared bicycles. In general, the p-median and MCLP were used to determine the optimal locations of the shared stations. These studies proved the usefulness of locationallocation models as a method for determining the optimal location to meet demand.

Previous studies were generally based on comparing the two

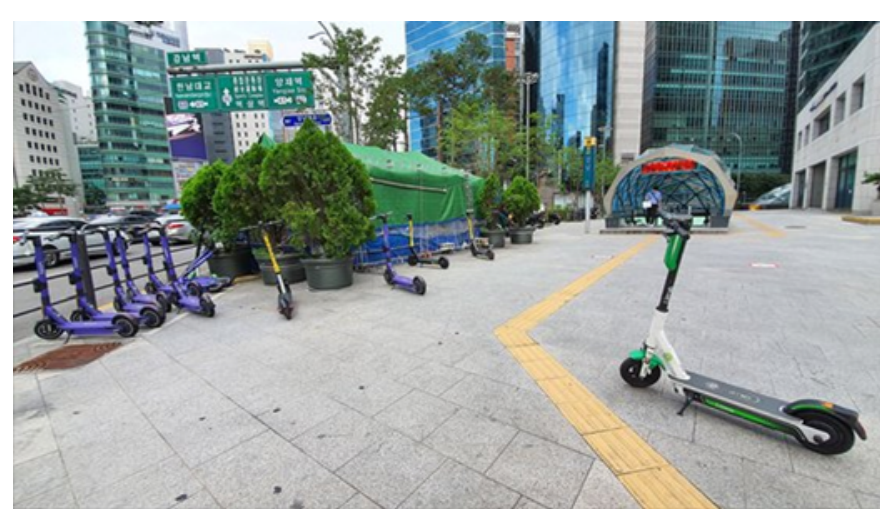

(a)

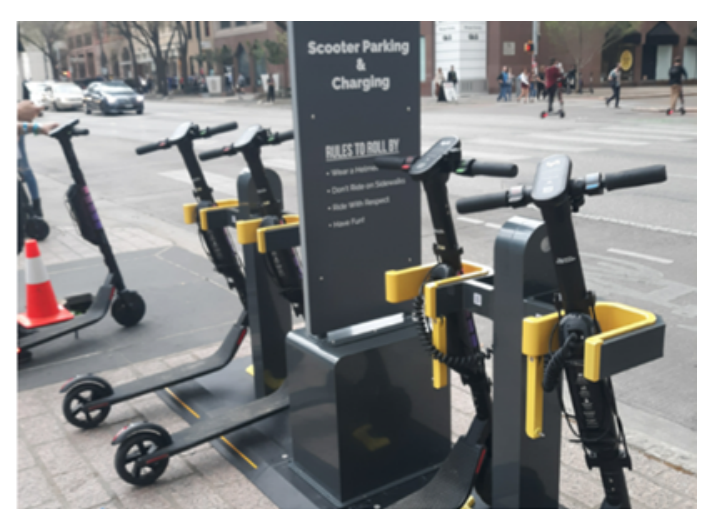

(b)

Fig. 1. Operation of: (a) DS (Park, 2020), (b) SS (Dickey, 2019) 
methods from the perspective of consumers and suppliers. In a covering-based model on the supplier side, in addition to the MCLP, the location set covering problem (LSCP) is highly utilized for selecting locations for social infrastructure. Another study employed the LSCP and p-median models together to select a location with the optimal number of facilities to service all the demand points in a particular area (Lee et al., 2019). This approach calculates the optimal number of facilities that could be deployed (non-overlapping, so that resources were not wasted) and then utilized the p-median model to derive efficient locations for the facilities.

After reviewing these earlier studies, it is found that there is a lack of research on the establishment of DS service areas. Despite many studies have suggested the need for a service that combines the two methods, none have also specifically proposed such a service. As the aforementioned discussion implies that it is important to reflect the users' preference of PMS services and potential demand, this study proposes a framework for determining service areas and station locations by conducting a case study in Geumjeong-gu, Busan, Korea.

\section{Methodology}

In this study, personal mobility vehicle, among various types of modes, was conceptually defined as e-bicycles and e-scooters, that is, single-person vehicles driven by electric power providing

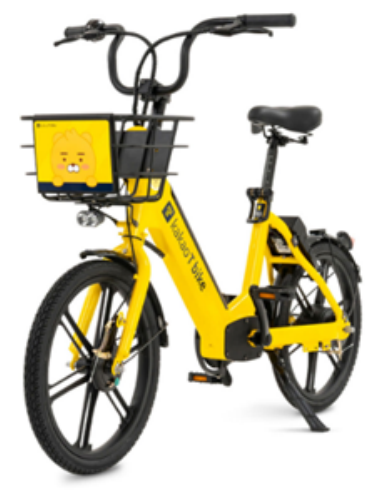

(a)

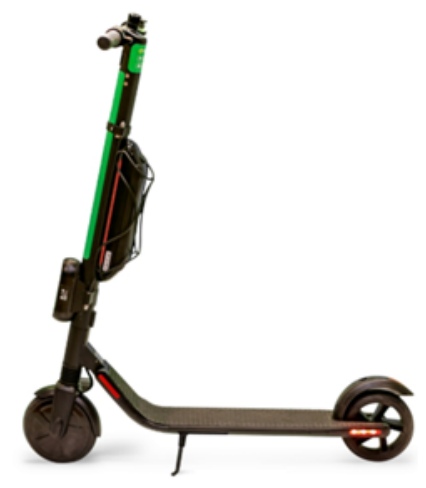

(b)
Fig. 2. Defined: (a) e-Bike (KaKao Mobility, 2020), (b) e-Scooter (G. bike, 2019)) a speed of less than $25 \mathrm{~km} / \mathrm{h}$. The defined devices are shown in Fig. 2. This study consisted of two main steps. First, to operate PMS service effectively, DS service area was prioritized in accordance with the intention to use it. Next, using an estimate of travelers, an appropriate station location (in a place that users preferred) was determined within the DS service area. Table 1 summarizes the tasks performed at each step.

\subsection{Setting Up the Dockless System (DS) Service Area for a Personal Mobility Sharing (PMS) Service}

As discussed in the previous chapters, this study aims to provide efficient PMS operations by selecting DS service areas and station installations that reflect user intentions. First, we used stated preference (SP) survey data to investigate user's preference of using dockless PMS service to encompass the service area.

\subsubsection{Step 1-1. Data Collection and Variable Setting}

Short-distance buses, autos, motorcycles, and walk can be replaced by personal mobility. Thus, travel time and distance are the main factors influencing the choice of an alternative travel mode and should be considered as major variables in the choice of PMS. Similarly, the selection of walking/bicycle modes of transportation is negatively affected by the degree of slope (Rodriguiz and Joo, 2004; Frade and Ribeiro, 2014). Therefore, we considered travel distance and slope as the main factors in users' intention to select dockless PMS service. For this purpose, this study collected data on the preference of dockless PMS service when traveling between the respondent's point of origin and the nearest urban railway station. We used the network analysis tool in ArcGIS to calculate the shortest travel distance between the origin and destination (urban railway station), and calculated the elevation difference to acquire the average slope of the shortest travel route. Additionally, the weather condition, the use of roadways or bicycle roads and fares of PMS service were used as variables in the model.

\subsubsection{Step 1-2. Logistic Regression Model Prediction for Use of Dockless PMS}

Using the variables, a probability model about using dockless PMS was constructed based on a logit (i.e., logistic regression) model. A logistic regression model is a random selection model that aims to predict each event that will occur in the future by

Table 1. Framework

Step 1. Set dockless system (DS) service area of personal mobility sharing (PMS) service

- Derive a logit-based probability model that reflects regional characteristics using survey data

- After dividing the case study area by 100 meters grid, set target zones with accessible roads within $500 \mathrm{~m}$ of them, setting each zone with a probability of users using dockless PMS over $50 \%$ as a DS service area of PMS
Step 2. Station positioning

- Select the cell center point of the $100 \mathrm{~m}$ unit zone designated as the DS service area of PMS as station candidate

- Use a mobile device data as the number of potential users and demand points

- Calculate the optimal number of stations through the location to allocation model (LSCP)

- Select the optimal PMS station location through the location to allocation model (p-median) 
expressing the relationship between the dependent and independent variables as a function. In this study, we used a logit model with qualitative variables as the dependent variable:

$$
\begin{aligned}
& \log \frac{\operatorname{prob}(x)}{1-\operatorname{prob}(x)}=\beta_{0}+\sum \beta_{k} x_{k}, \\
& \operatorname{prob}(x)=\frac{\exp \left[\beta_{0}+\sum \beta_{k} x_{k}\right]}{1+\exp \left[\beta_{0}+\sum \beta_{k} x_{k}\right]},
\end{aligned}
$$

where

$\operatorname{prob}\left(y=1 \mid x_{1} \cdots x_{1}\right)=$ Probability that the dockless PMS service will be selected

$x_{k}=$ Variables related to device characteristics that influence the choice of dockless PMS service

$\beta_{0}=$ Constant

$\beta_{k}=$ Parameter estimated from model

Through a binomial logistic regression analysis, the probability that dockless PMS service will be selected can be estimated. The basic formula for the binomial logit model is given by Eq. (1), and represents the relationship between the dependent and independent variables. The probability of the occurrence of an expected event can be expressed by Eq. (2).

\subsubsection{Step 1-3. Setting the DS Service Area of the PMS Service}

Preferentially, the case area was divided by 100 meters grid to define a cell. In this process, the logistic regression model derived in Step 1-2 was applied to the center point of a cell with a road accessible within $500 \mathrm{~m}$. Subsequently, it is proposed to designate dockless PMS service area for a unit area with a probability of more than $50 \%$.

\subsection{Selecting the Location of a PMS Station}

Through a review of previous studies, we found that it is necessary to operate the PMS as a DS in low demand regions and as SS in high demand. The locations for sharing stations with high potential demand within the DS service area were determined using an optimization model. Specifically, it was important to set a return rule rather than a rental rule for the station to be actively utilized without losing the advantages of DS. Therefore, we proposed to determine the return of the device based on the distance from the station and it can be explained as follows:

In DS service area, return to station occurs if $d_{m n} \leq \mathrm{a}$ and return to site $\mathrm{m}$ if $a \leq d_{m n} \leq \theta$, otherwise the device is not returned, where

$a=$ Distance limiting the return of dockless from the station

$d_{m n}=$ Shortest distance between $m$ and $n$

$m=$ Index for the return point the user wants

$n=$ Index for PMS station

$\theta=$ Limited DS area through geofencing technology

DS intends to restrict parking outside the service area through geo-fencing technology, similar to marketing services used by existing companies. This technology is utilized by a GPS receiver equipped to the device.

\subsubsection{STEP 2-1. Collecting Potential Demand Data}

Recently, it has become possible to collect mobile device user's location in real-time from communication data. As more than 95\% of Korean residents uses mobile devices, device's locationbased mobility data can be very promising to observe commuters and travelers in specific geographic areas. Further, it has been suggested that this data collection method may replace the census data commonly used to determine potential demand (Park and Sohn, 2017; Lee et al., 2018). Therefore, we used the average daily travelers, and aggregated by cells where falls in of $100 \times$ 100 meters, to specify potential demand points.

\subsubsection{STEP 2-2. Selecting Station Candidates}

For location distribution, it was necessary to set up a candidate area for the SS. In this study, it is determined that the SS should be located within DS area with a wide service range. Thus, we defined the candidate areas as the center points of the cells within the produced DS area.

\subsubsection{STEP 2-3. Selecting the Location of the Stations}

Location-allocation models aim to determine an optimal location for various urban facilities to meet the objectives of location decisions. Therefore, location-allocation models appear in various forms depending on their objective functions and constraints. In this study, LSCP is applied to determine the minimum number and location of stations, which is mostly and commonly used for selecting the facility location. Then, the optimized location was selected for the PMS stations by finding a point that minimized the sum of the total travel distances of users through the Pmedian model. The mathematical model used in this study is explained through the notation, and the contents are as follows:

$$
\begin{aligned}
d_{i j}= & \text { Shortest distance between demand point } i \text { and station } \\
& \text { point } j \\
h_{i}= & \text { Traveler size at demand point } i \\
i= & \text { Index for demand points } \\
j= & \text { Index of potential station points } \\
P= & \text { Number of stations to be selected } \\
s= & \text { Range limit of the demand point that can be included } \\
& \text { in the station } \\
W= & \text { Set of potential station points } \\
W_{i}= & \text { Set of station points within a distance } s \text { from demand } \\
& \text { point } i
\end{aligned}
$$

First, for the LSCP model, the determinant and objective variables can be explained as follows:

Decision variable : $x_{j}=1$ if the facility is located at $j$, or 0 otherwise

$$
\begin{aligned}
\operatorname{Minimiz} & \sum_{j \in W} x_{j}, \\
\text { Subject to } & \sum_{j \in W_{i}} x_{j} \geq 1(\text { for all } i), \\
& x_{j} \in\{0,1\}(\text { for all } j), \\
& W_{i}=\left\{j \in W \mid d_{i j} \leq s\right\} .
\end{aligned}
$$




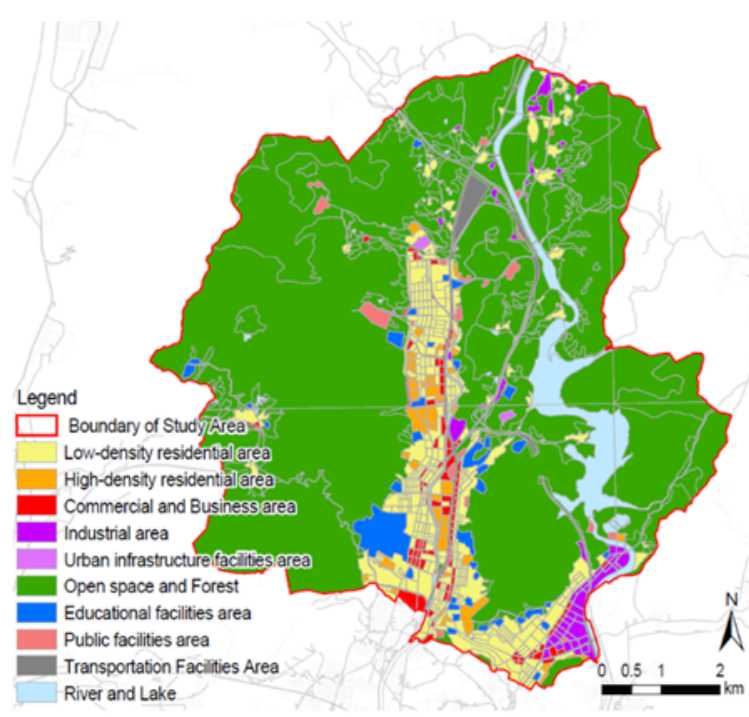

(a)

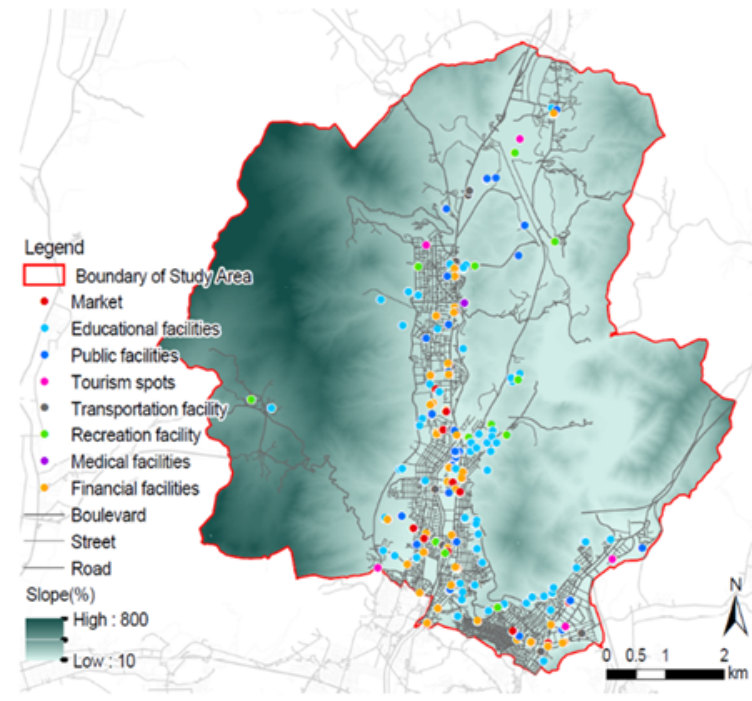

(b)

Fig. 3. Land Use, Facility Status, and Slope in Study Area: (a) Land Use, (b) Population-Induced Facilities and Slope

The LSCP aims to minimize the total number of facilities $x_{j}$ according to the objective function in Eq. (3). As, all demand points $i$ are defined to allocate at least one station in the area, and there is still possibility that the facility will be installed indiscriminately, a definition of $d_{i j}$ is included within distance $s$, as shown in Eq. (6), reflecting accessibility.

Next, the p-median model can be described as follows:

Decision variable:

$x_{j}=1$ if the facility located at $j$, or 0 otherwise

$y_{i j}=1$ if the demand of point $i$ is assigned to station $j$, or 0 otherwise

$$
\begin{aligned}
\text { Minimize } & \sum_{i} \sum_{j} h_{i} d_{i j} y_{i j}, \\
\text { Subject to } & \sum_{j} y_{i j}=1(\text { for all } i), \\
& \sum_{j} x_{j}=P(\text { for all } i), \\
& y_{i j} \leq x_{j}(\text { for all } i, j), \\
& x_{j}, y_{i j} \in\{0,1\}(\text { for all } i, j) .
\end{aligned}
$$

The p-median model determines the location of the facility to minimize the sum of the distances between all the demand points and the nearest facility according to the objective function Eq. (7). Unlike other public transportation facilities, the accessibility of the PMS service will have the greatest impact on use, so it is reasonable to use the p-median model. First, prior to the analysis, it was important to determine the number of facilities required for the analysis. Next, the analysis was conducted satisfying the constraints of Eqs. (8) to (11), and the study was conducted on the assumption that demand points cannot be serviced through more than one facility.

\section{Case Study}

The empirical analysis of the framework of this study was conducted for Geumjeong-gu, an administrative district in Busan, Korea. Due to Busan's hilly terrain, cycling is not common except for leisure purposes and the roadway conditions for bicycles and sharing devices are insufficient. In this situation, PMS services are being introduced and rapidly activated around universities and commercial areas. However, there has been issues about escooters left unattended on or in the middle of curbside conflicting pedestrian flows, and a consequent measurement has been highly demanded.

The land use, facility status, and slope of Geumjeong-gu are shown in Fig. 3. The data were collected from the National Spatial Data Infrastructure (2020) and the Statistical Data Center (2020). Considering the main arterial crossing the area vertically, the western residential area is located in a hilly area as shown on the right of Fig. 3, and because of the lack of accessibility to an urban railway station, the resistance to walking and using bicycles is high. Geumjeong-gu (considered a location requiring PMS) was targeted as the case study area because of its high traffic volume and traffic congestion created by national universities, commercial facilities, and highway interchanges during am and pm peak hours.

\subsection{Setting the DS Service Area for PMS}

\subsubsection{STEP 1-1. Data Collection and Variable Setting} The data were collected from a survey targeting residents with

Table 2. Outline of Data

\begin{tabular}{ll}
\hline Classification & Contents \\
\hline Survey method & Online survey \\
Date & $2019.5 .3-2019.5 .22$ \\
Validity of survey & Use 78 out of 598 parts investigated in \\
& Geumjeong-gu, Busan, Korea \\
\hline
\end{tabular}


the age of 16 or older living in Busan and it is summarized in Table 2. From the survey, it is found that the significant variables are varied by administrative districts and 'Geumjeong-gu' was selected as a geographical boundary to satisfy the purpose of this study. From the total data respondents of of 598, 78 data respondents were selected for analysis. According to Hsieh et al. (1998), when the number of samples used in a paper is based on a twosided test (odds ratio 2.04; significance level $\alpha=0.1$; and power 0.8 ), the validity of the model can be secured with the number of samples in the study. The data were SP-designed through eight scenarios prepared by dividing the variable levels as shown in Table 3. Preference of dockless PMS service closest to the nearest urban railway station was investigated based on weather, PMSaccessible roads, and fares. The travel distances and average slopes to the nearest urban railway station were calculated based on the survey information which includes respondent origin addresses.

The variables were constructed based on the preceding steps. The names of specific variables are fare $\left(x_{1}\right)$, road to allow PMS $\left(x_{2}\right)$, weather $\left(x_{3}\right)$, slope $\left(x_{4}\right)$, and trip length $\left(x_{5}\right)$. Variable descriptions and basic statistics are listed in Table 4. A total of 624 samples were selected according to the coding method of the dependent variables, as collected through the eight scenarios.

\subsubsection{STEP 1-2. Logistic Regression Model Prediction for the Use of Dockless PMS}

The results of the analysis showed that the lower the fare (-) and the clearer the weather $(+)$, the greater the PMS modal share. The use of bikeways was not significant as there were a small number of bikeways in the study area. In addition, the results showed that the shorter the travel distance (-) and higher the average slope $(+)$, the greater the modal share for the PMS service. Using the results of the analysis in Table 5, the probability of using the PMS service (i.e., DS) is shown in Eq. (12):

$\operatorname{prob}(x)=\frac{\exp \left[-0.765 x_{1}+0.322 x_{2}+1.413 x_{3}+0.066 x_{4}-0.626 x_{5}-0.977\right]}{1+\exp \left[-0.765 x_{1}+0.322 x_{2}+1.413 x_{3}+0.066 x_{4}-0.626 x_{5}-0.977\right]}$.

Table 3. Designed Stated Preference (SP) Variable Level

\begin{tabular}{lllll}
\hline Classification & Unit & Level 1 & Level 2 & Level 3 \\
\hline Weather & - & Sunny & Rain & - \\
Allowed road for PMS & - & Bicycle roads allowed & Road & - \\
Fare & 500 KRW/10 min & 1 & 2 & 3 \\
\hline
\end{tabular}

Table 4. Variable Descriptions and Basic Statistics

\begin{tabular}{|c|c|c|c|c|c|c|c|}
\hline \multicolumn{3}{|l|}{ Classification } & \multirow{2}{*}{$\begin{array}{l}\text { Freq. (\%) } \\
492(78.8)\end{array}$} & \multirow[t]{2}{*}{ Mean } & \multirow[t]{2}{*}{ Std. error } & \multirow[t]{2}{*}{ Min } & \multirow[t]{2}{*}{ Max } \\
\hline Dependent variable & Preference of dockless PMS services & $0=$ Not use & & & & & \\
\hline & & $1=\mathrm{Use}$ & $132(21.2)$ & & & & \\
\hline & Road to allow PMS & $0=$ Road & $312(50.0)$ & & & & \\
\hline & & $1=$ Bicycle roads allowed & $312(50.0)$ & & & & \\
\hline & Slope $(\%)$ & & $624(100.0)$ & 4.33 & 6.12 & 0.00 & 30.93 \\
\hline & Trip length $(\mathrm{km})$ & & $624(100.0)$ & 0.72 & 0.58 & 0.01 & 5.01 \\
\hline
\end{tabular}

Table 5. Probability Model for Using Dockless Service

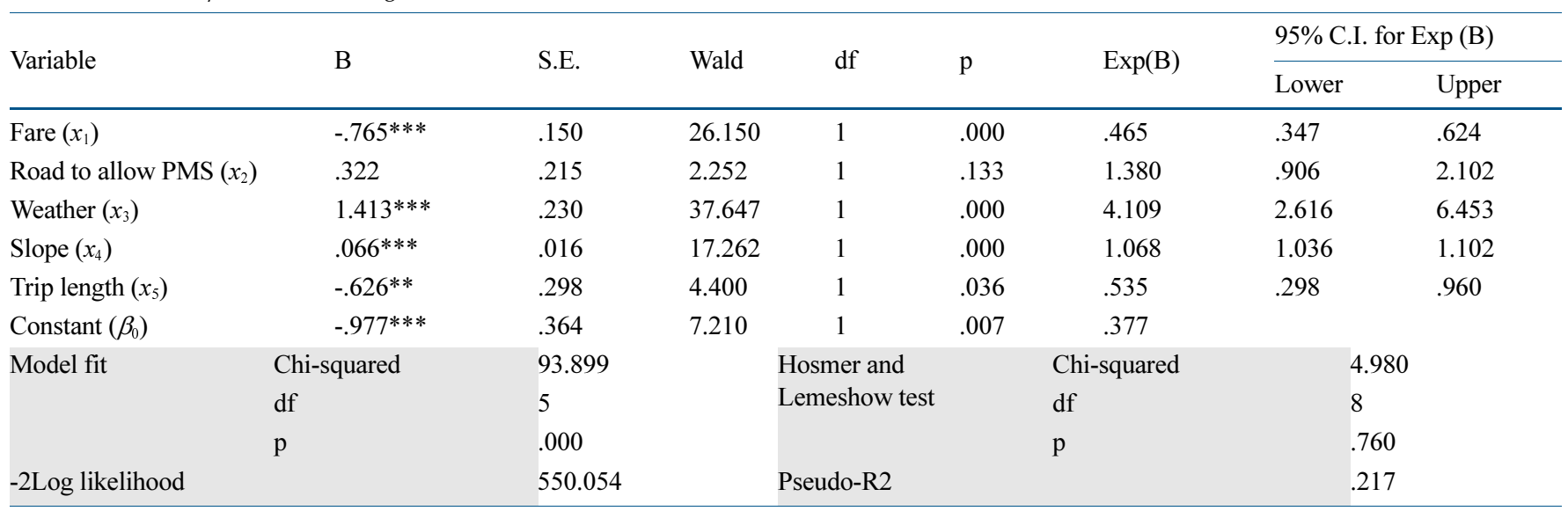

Note: $* * * \mathrm{P}<0.01, * * \mathrm{P}<0.05$ 


\subsubsection{STEP 1-3. Setting DS Service Area for PMS}

To establish the service area, the route to an urban railway station was found for the points where there was a usable road within $500 \mathrm{~m}$ of the center point of the $100 \mathrm{~m}$ grid. The probability of using PMS services per unit area was calculated using Eq. (12), and the service areas were areas with values of $50 \%$ or more. As the range of the service area varied according to the supply characteristic variable of the PMS, this study assumed a scenario in which the maximum used area could appear to calculate the maximum number of SSs required in Step 2. Accordingly, it was possible to determine the service area with conditions of a scenario where free fare, sunny weather, and bicycle road use were allowed, as shown in Fig. 4(a). It was found that $33.04 \%$ of the case areas had more than a $50 \%$ probability of commuters using the PMS service. The service area was wider to the west, with a higher slope, when viewed from the north-south arterial.

\subsection{Selecting the Location of the PMS Station}

\subsubsection{STEP 2-1. Collecting Potential Demand Data}

The daily average traveler data were collected hourly based on communication data. The data was collected in 2018 and were aggregated through location information generated by people subscribing to a particular mobile carrier. There were approximately 2 million cases collected on an hour basis and divided into $100 \mathrm{~m}$ units, as shown in Fig. 4(b). The traveling population were mainly distributed around the main populationinducing facilities and residential areas.

\subsubsection{STEP 2-2. Selecting Station Candidates}

In Fig. 4(a), the cell center point of the service area where the probability of using PMS was more than $50 \%$ was set as the candidate station area.

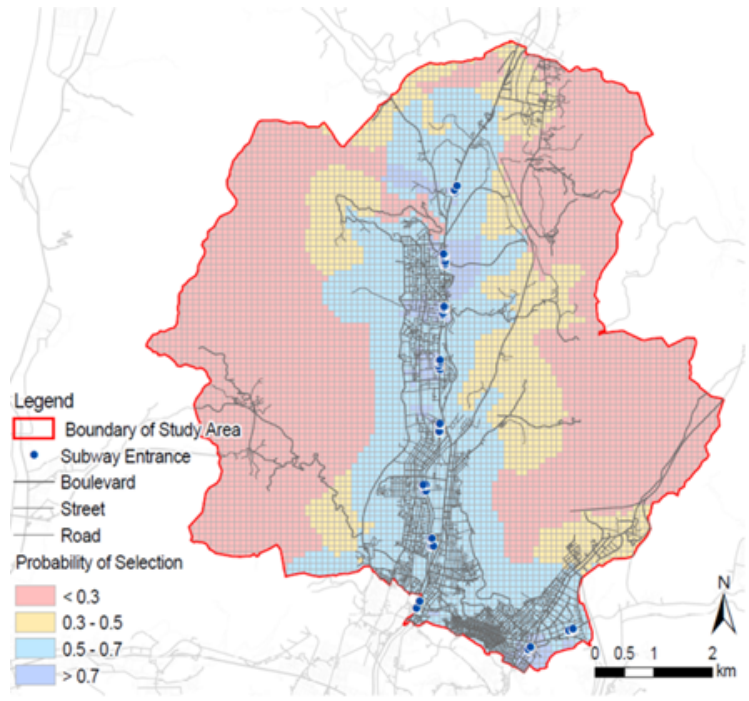

(a)

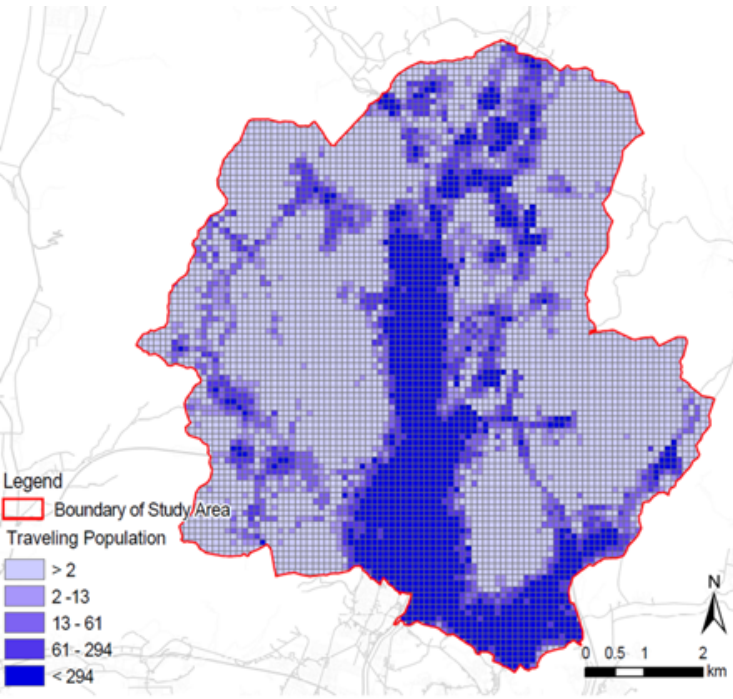

(b)

Fig. 4. Dockless Service Area and Traveling Population: (a) Dockless Service Area, (b) Traveling Population

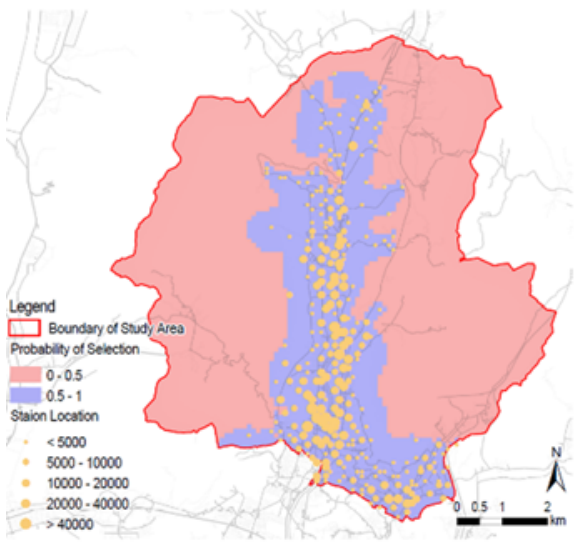

(a)

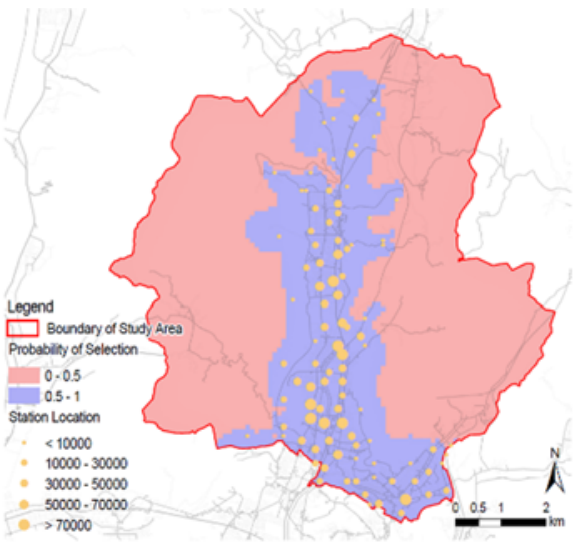

(b)

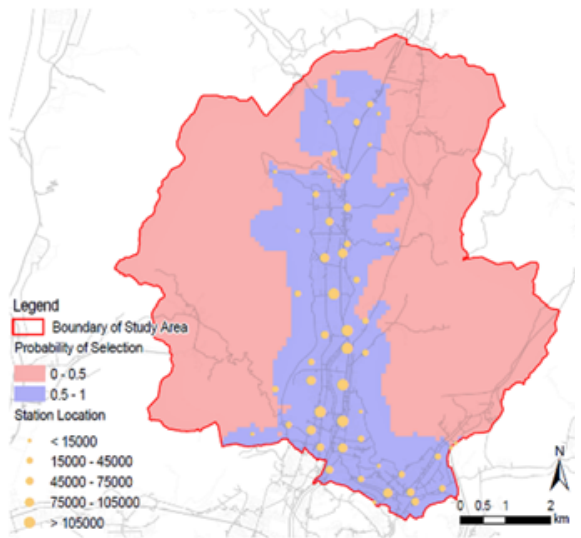

(c)

Fig. 5. Results from the Location Set Covering Problem (LSCP) Model: (a) Coverage Distance 200 m, (b) Coverage Distance 400 m, (c) Coverage Distance $600 \mathrm{~m}$ 


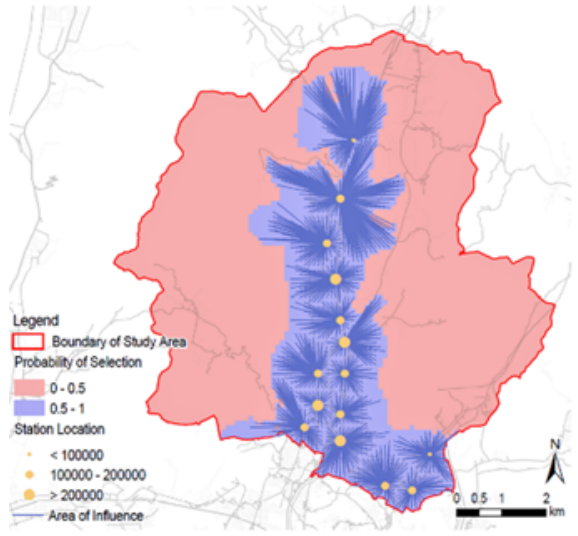

(a)

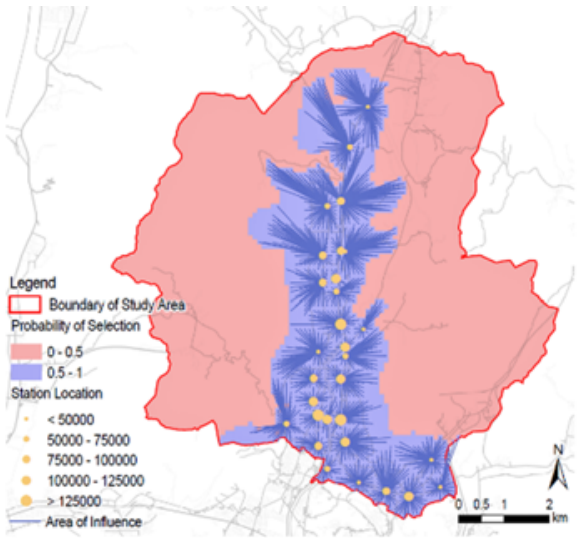

(b)

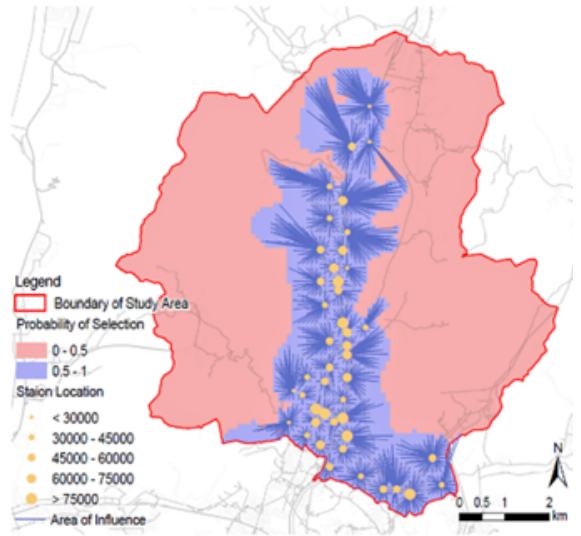

(c)

Fig. 6. Results from the p-Median Model: (a) 15 Stations, (b) 30 Stations, (c) 45 Stations

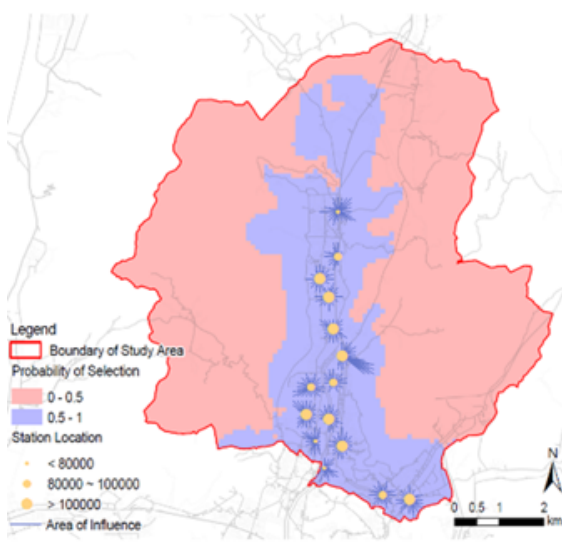

(a)

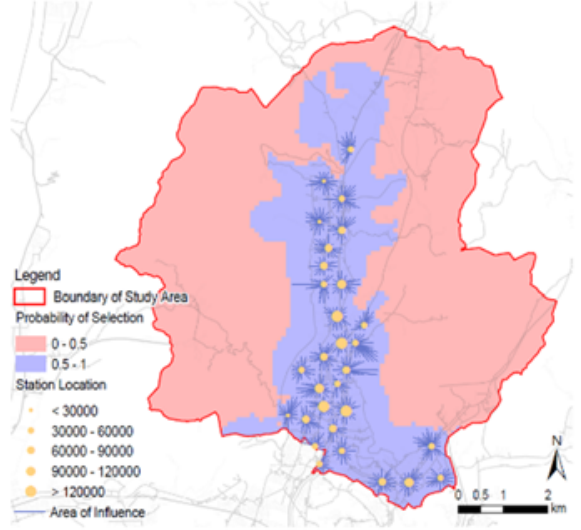

(b)

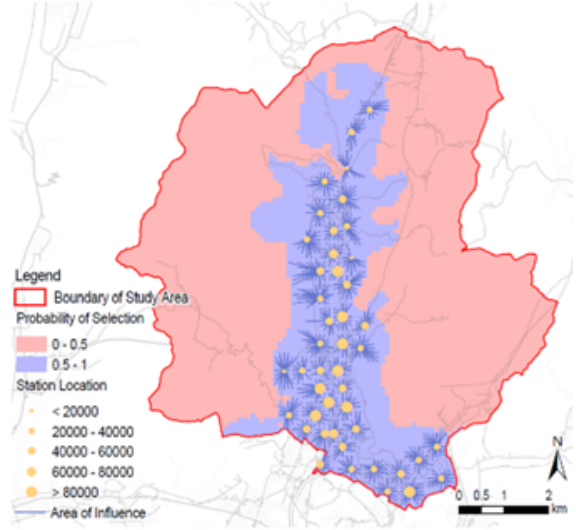

(c)

Fig. 7. Results from the p-Median Model considering Accessibility within 400 m: (a) 15 Stations, (b) 30 Stations, (c) 45 Stations

\subsubsection{STEP 2-3. Selecting Station Locations}

The location-allocation analysis was conducted using two models, namely, LSCP and p-median. The average daily traveling population was analyzed at the demand point and the LSCP model was used to determine the minimum number of stations required. We identified the minimum number of stations required for $200 \mathrm{~m}$, $400 \mathrm{~m}$, and $600 \mathrm{~m}$ based on $400 \mathrm{~m}$, that is, an approximate walking distance of $5 \mathrm{~min}$, for the coverage range of PMS stations and demand points. Fig. 5 shows the locations and sizes of the allocated demand at 295, 100, and 53 stations required for $200 \mathrm{~m}, 400 \mathrm{~m}$, and $600 \mathrm{~m}$, respectively. This was based on the premise that services were available in all demand areas. Moreover, an installation exceeding the derived number of stations could cause inefficiencies as previously discussed; thus, policymakers should consider this when planning the number of stations.

Some of the analysis results using the p-median model and specifying the number of stations are shown in Fig. 6. However, the derived results were judged to be inefficient, as they did not consider the travel distance to the PMS station. Therefore, the results obtained by limiting the pedestrian access distance to the station to a maximum of $400 \mathrm{~m}$, that is, an approximate walking distance of $5 \mathrm{~min}$, are shown in Fig. 7, and it is noticeable that the
Table 6. Variation of the Percentage of Demand Covered by Number of Stations and Distance Traveled

\begin{tabular}{lllll}
\hline \multirow{2}{*}{$\begin{array}{l}\text { Number of } \\
\text { stations }\end{array}$} & \multicolumn{4}{l}{$\begin{array}{l}\text { Percentage of potential demand covered when a station } \\
\text { within several meters is selected }\end{array}$} \\
\cline { 2 - 5 } & $200 \mathrm{~m}$ & $300 \mathrm{~m}$ & $400 \mathrm{~m}$ & $500 \mathrm{~m}$ \\
\hline 15 & $35.40 \%$ & $51.30 \%$ & $66.62 \%$ & $79.22 \%$ \\
30 & $52.02 \%$ & $72.24 \%$ & $85.79 \%$ & $95.71 \%$ \\
45 & $63.06 \%$ & $84.03 \%$ & $95.37 \%$ & $99.24 \%$ \\
60 & $67.01 \%$ & $91.43 \%$ & $98.45 \%$ & $99.98 \%$ \\
75 & $77.97 \%$ & $95.72 \%$ & $99.82 \%$ & $100.00 \%$ \\
90 & $82.87 \%$ & $97.67 \%$ & $99.99 \%$ & \\
100 & $85.66 \%$ & $98.79 \%$ & $100.0 \%$ & \\
\hline
\end{tabular}

station locations are differently distributed between Figs. 6 and 7. Table 6 shows that the percentage of demand accessible to the stations increases as the maximum access distance and number of stations increase. Conversely, the maximum access distance to the station can be used as a basis for prohibiting the return of the DS if users want to return it within a certain distance from the station after using the PMS. 


\section{Discussion}

This study proposed a methodological framework for determining the locations of DS service areas and stations in an effort to discuss the efficient introduction of PMS. In addition, it focused on utilizing and applying data for the case areas. This study raises the following points for further discussion.

The location of the station, determined through the data of the travelers used in the study, can be viewed as distributed around arterials and population-inducing facilities. In the selected location, the station can be installed in two ways. First, most of these locations have relatively large public spaces and pedestrian roads. Therefore, it seems that there will be no difficulty in preparing a PM station that can park approximately 10 devices in the parking space of one car. Second, if there is not enough space, a place can be secured by associating it with a building. Convenience stores often provide services that solve the charging and parking of devices. As in this case, a linkage with a building takes advantage of the size of the device. In addition, installing the station of the device at the main entrance of a building can increase the accessibility of the device and supply space for the station.

Next, as a result of the study, the capacity of the station can be set by the ratio of the demand allocated to the station to the estimated total potential demand. There is no need to provide parking space for all devices at all times to complement the DS. However, to improve the accessibility of devices, it is necessary to maintain a minimum number of devices for the station. Also, it is important to calculate the capacity of the station in terms of the number of devices to be returned for proper parking, and the number of devices that need to be increased in response to the demand. It is also believed that the devices will need to be relocated so that the station can maintain a minimum number of devices. The main findings of this study are summarized as follows:

1. It is discussed how to support the location planning of the service area and station to reduce the negative effects that could potentially arise from the introduction and use of the PMS system.

2. This study assumes that PMS services will be used around urban railroads, and proposes a methodology to support effective utilization plans. In particular, the purpose was to suggest a definition of the DS area and its method, which could not be found in previous studies and existing services. Therefore, defining service areas through modes and regional characteristics is considered an important differentiating factor in this study. These results can be used as basic data for transportation plans, such as reorganizing other modes for areas other than service areas.

3. The existing demand forecasting for facility planning has a limitation in that projections are based on transferring census data (such as household travel survey data) to the total population. However, this study used the average hourly traveler data. Compared to the census data, the results for the station locations were displayed with higher accurately.
4. The framework of this study was applied as a case study in Geumjeong-gu, an administrative district in Busan, Korea. The case area is characterized by highly populated residential areas, poor urban railway access, and hilly terrain not suitable for walking and cycling. Therefore, the target area fits to the introduction of PMS services, due to the poor access to transit system and difficulty in walking or biking. Furthermore, based on the model practice and results, this framework transferability can be suggested in other regions.

\section{Conclusions}

This study focused on two types of PMS service system operation methods (SS and DS) in relation to the PMS(s) for which services are wide spreading. As it was necessary to combine and operate the two systems for efficient city management, a framework for the establishment of service areas and station installations was proposed by utilizing related documents and data. Based on the results of previous research, that is, a wider range of services is possible with a device with fewer DSs than SSs, DSs should operate in a wide range of low-density areas, and SSs should be deployed in areas with large foot traffic and operations primarily preferred by users within the DS service area.

This indicates the following framework, namely, that the DS service area can established based on the probability of the user using dockless PMS. Based on the potential demand, the minimum required number of facilities is calculated through the LSCP model, and the station locations are determined through the p-median model to minimize the travel distance of users to their respective facility points.

It applied this to the case area and the policy implications are concluded as follows. The study's results suggest that the service can be operated flexibly based on utilizing major supply characteristics such as fares and weather. The number of stations can be determined according to the available budget, and e-bike or e-scooter racks can be distributed the based on the demands allocated to stations. In addition, no-parking zone should be designated in consideration of the return of DSs, and a station including charging facilities for electric-powered vehicles needs to be installed. If these are considered, the framework proposed in this study can make a positive change in the safety and utility of urban traffic. Despite the sound modeling approaches, analysis, and findings, there are still some limitations left for further improvement. First, the number of samples used in the logistic regression analysis in Step 1-2 was 78, which is not enough to support the results. Second, this study was not considered socioeconomic characteristics. Lastly, the accessible distance was modeled not actually observed. With complementary research followed by this study, it would be possible to specify the preference with higher accuracy, and to investigate latent demand.

Supporting electric personal mobility services as a connecting mode to transit system will thrive community's smart development and its sustainability. In particular, active support for low-emission transportation mode is believed to be a concrete strategy for 
establishing and integrating future transportation services. As such, this study contributes a solid commitment as a basic step toward building smart and integrated transportation system.

\section{Acknowledgments}

This work was financially supported by the Korea Ministry of Land, Infrastructure and Transportation (MOLIT) as the (Innovative Talent Education Program for Smart City).

\section{ORCID}

Minhye Choi ๑ http://orcid.org/0000-0003-0766-7767

Hunyoung Jung ๑ http://orcid.org/0000-0002-3697-5622

Hyeryeong Lee $\odot$ http://orcid.org/0000-0002-8492-5398

\section{References}

Almannaa MH, Ashqar HI, Elhenawy M, Masoud M, Rakotonirainy A, Rakha H (2020) A comparative analysis of e-scooter and e-bike usage patterns: Findings from the City of Austin, TX. International Journal of Sustainable Transportation 15(7):571-579, DOI: 10.1080/ 15568318. 2020.1833117

Bai S, Jiao J (2020) Dockless E-scooter usage patterns and urban built environments: A comparison study of Austin, TX, and Minneapolis, MN. Travel Behaviour and Society 20:264-272, DOI: 10.1016/ j.tbs.2020.04.005

Chen L, Zhang D, Pan G, Ma X, Yang D, Kushlev K, Zhang W, Li S (2015) Bike sharing station placement leveraging heterogeneous urban open data. Proceedings of the 2015 ACM international joint conference on pervasive and ubiquitous computing, September $7-$ 11, Osaka, Japan

Clewlow RR (2019) The micro-mobility revolution: The introduction and adoption of electric scooters in the united states. Transportation research board 98th annual meeting, January 13-17, Washington DC, USA

Dickey MR (2019) Swiftmile will become the 'gas station' for electric bikes and scooters in Austin. TechCrunch, Retrieved October 25, 2019, https://techcrunch.com/2019/10/24/swiftmile-will-become-thegas-station-for-electric-bikes-and-scooters-in-austin/

Faghih-Imani A, Eluru N (2015) Analysing bicycle-sharing system user destination choice preferences: Chicago's Divvy system. Journal of Transport Geography 44:53-64, DOI: 10.1016/j.jtrangeo.2015.03.005

Fang K, Agrawal AW, Steele J, Hunter JJ, Hooper AM (2018) Where do riders park dockless, shared electric scooters? Findings from San Jose, California. Project 1713, Mineta Transportation Institute Publications, San Jose, CA, USA

Frade I, Ribeiro A (2014) Bicycle sharing systems demand. ProcediaSocial and Behavioral Sciences 111:518-527, DOI: 10.1016/ j.sbspro.2014.01.085

Frade I, Ribeiro A (2015) Bike-sharing stations: A maximal covering location approach. Transportation Research Part A: Policy and Practice 82:216-227, DOI: 10.1016/j.tra.2015.09.014

Gao L, Ji Y, Yan X, Fan Y, Guo W (2021) Incentive measures to avoid the illegal parking of dockless shared bikes: The relationships among incentive forms, intensity and policy compliance. Transportation 48:1033-1060, DOI: 10.1007/s11116-020-10088-x

García-Palomares JC, Gutiérrez J, Latorre M (2012) Optimizing the location of stations in bike-sharing programs: A GIS approach. Applied Geography 35(1-2):235-246, DOI: 10.1016/j.apgeog.2012.07.002

G. bike (2019) Gcooter. Retrieved October 16, 2019, https://gbike.io/

Hollingsworth J, Copeland B, Johnson JX (2019) Are e-scooters polluters? The environmental impacts of shared dockless electric scooters. Environmental Research Letters 14(8):1-10, DOI: 10.1088/ 1748-9326/ab2da8

Hsieh FY, Bloch DA, Larsen MD (1998) A simple method of sample size calculation for linear and logistic regression. Statistics in Medicine 17(14):1623-1634, DOI: 10.1002/(SICI)1097-0258(19980730) 17:14<1623::AID-SIM871>3.0.CO;2-S

Ji Y, Ma X, He M, Jin Y, Yuan Y (2020) Comparison of usage regularity and its determinants between docked and dockless bike-sharing systems: A case study in Nanjing, China. Journal of Cleaner Production 255(120110), DOI: 10.1016/j.jclepro.2020.120110

KaKao Mobility (2020) Bike. Retrieved December 17, 2020, https:// www.kakaomobility.com/contents/10

Kim M, Kim H, Kim HK (2019a) Study on defining FMM and LMM service area using smart mobility in Haeundae-gu, Busan. Journal of Korean Society of Transportation 37(3):245-253, DOI: 10.7470/ jkst.2019.37.3.245

Kim S, Oh S, Choi K (2019b) Bike travel pattern analysis for station free bike sharing system in Suwon. Journal of Korean Society of Transportation 37(2):110-123, DOI: 10.7470/jkst.2019.37.2.110

Korea National Spatial Data Infrastructure Portal (2020) Land use. Retrieved July 27, 2020, http://data.nsdi.go.kr/dataset/20190801ds00001

Kwak JH (2020) The public transportation is uncomfortable... Commuting with shared kickboards and bikes. Hankookilbo, Retrieved May 5, 2020, https://www.hankookilbo.com/News/Read/202005251582043570 (in Korean)

Lazarus J, Pourquier JC, Feng F, Hammel H, Shaheen S (2019) Bikesharing evolution and expansion: Understanding how docked and dockless models complement and compete - A case study of San Francisco. Transportation research board 98th annual meeting, January 13-17, Washington DC, USA

Lee H, Chen M, Pham HT, Choo S (2019) Development of a decision making system for installing unmanned parcel lockers: Focusing on residential complexes in Korea. KSCE Journal of Civil Engineering 23(6):2713-2722, DOI: 10.1007/s12205-019-1398-y

Lee WK, Sohn SY, Heo J (2018) Utilizing mobile phone-based floating population data to measure the spatial accessibility to public transit. Applied Geography 92:123-130, DOI: 10.1016/j.apgeog.2018.02.003

Li J, Tang R (2019) Analysis of the choice behaviour towards docked and dockless shared bicycles based on user experience. International Review for Spatial Planning and Sustainable Development 7(2):143156, DOI: 10.14246/irspsda.7.2_143

Lin J, Yang T (2011) Strategic design of public bicycle sharing systems with service level constraints. Transportation Research Part E: Logistics and Transportation Review 47(2):284-294, DOI: 10.1016/ j.tre.2010.09.004

Luo H, Kou Z, Zhao F, Cai H (2019) Comparative life cycle assessment of station-based and dock-less bike sharing systems. Resources, Conservation and Recycling 146:180-189, DOI: 10.1016/j.resconrec. 2019.03.003

Nair R, Miller-Hooks E, Hampshire RC, Bušić A (2013) Large-scale vehicle sharing systems: Analysis of Vélib'. International Journal of Sustainable Transportation 7(1):85-106, DOI: 10.1080/15568318. 2012.660115

Park MJ (2020) Shared e-scooter scattered everywhere... Only 2,000 complaints about "Is it innovation?". JoongAng Ilbo, Retrieved 
September 1, 2020, https://news.joins.com/article/23861372 (in Korean)

Park C, Sohn SY (2017) An optimization approach for the placement of bicycle-sharing stations to reduce short car trips: An application to the city of Seoul. Transportation Research Part A: Policy and Practice 105:154-166, DOI: 10.1016/j.tra.2017.08.019

Rodriguez DA, Joo J (2004) The relationship between non-motorized mode choice and the local physical environment. Transportation Research Part D: Transport and Environment 9(2):151-173, DOI: 10.1016/j.trd.2003.11.001

Sa K, Lee S (2018) Analysis of physical characteristics affecting the usage of public bike in Seoul, Korea: Focused on the different influences of factors by distance to bike station. Journal of Korea Planning Association 53(6):39-59, DOI: 10.17208/jkpa.2018.11.53.6.39
Shaheen SA, Finson R (2003) Bridging the last mile: A study of the behavioral, institutional, and economic potential of the segway human transporter. Paper 03-4470, Transportation Research Board, Berkeley, CA, USA

Statistical Data Center (2020) Population. https://data.kostat.go.kr/sbchome/ serviceData/svcOfrDataList.do?curMenuNo=OPT_01_02_00_0

Tu Y, Chen P, Gao X, Yang J, Chen X (2019) How to make dockless bikeshare good for cities: Curbing oversupplied bikes. Transportation Research Record 2673(6):618-627, DOI: 10.1177/0361198119837963

Zhang Y, Lin D, Mi Z (2019) Electric fence planning for dockless bikesharing services. Journal of Cleaner Production 206:383-393, DOI: 10.1016/j.jclepro.2018.09.215 